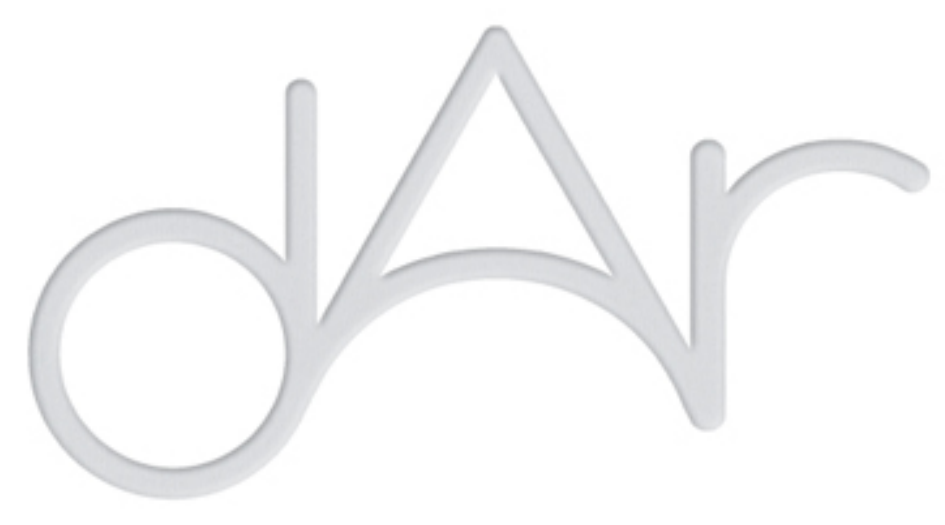

\title{
Methodological approach and first results of use-wear traces on flint tools through confocal microscope
}

\begin{tabular}{|c|c|}
\hline Autor(es): & $\begin{array}{l}\text { Cabornero, Claudia Santamaría; Cortés, Sergio Miguel Luengo; Ruiz, } \\
\text { Marta Navazo; Benito-Calvo, Alfonso; Lerma, Ignacio Martín }\end{array}$ \\
\hline Publicado por: & Imprensa da Universidade de Coimbra \\
\hline $\begin{array}{l}\text { URL } \\
\text { persistente: }\end{array}$ & URI:http://hdl.handle.net/10316.2/42861 \\
\hline DOI: & DOI:https://doi.org/10.14195/2182-844X_3_2 \\
\hline Accessed : & 26-Apr-2023 10:31:41 \\
\hline
\end{tabular}

A navegação consulta e descarregamento dos títulos inseridos nas Bibliotecas Digitais UC Digitalis, UC Pombalina e UC Impactum, pressupõem a aceitação plena e sem reservas dos Termos e Condições de Uso destas Bibliotecas Digitais, disponíveis em https://digitalis.uc.pt/pt-pt/termos.

Conforme exposto nos referidos Termos e Condições de Uso, o descarregamento de títulos de acesso restrito requer uma licença válida de autorização devendo o utilizador aceder ao(s) documento(s) a partir de um endereço de IP da instituição detentora da supramencionada licença.

Ao utilizador é apenas permitido o descarregamento para uso pessoal, pelo que o emprego do(s) título(s) descarregado(s) para outro fim, designadamente comercial, carece de autorização do respetivo autor ou editor da obra.

Na medida em que todas as obras da UC Digitalis se encontram protegidas pelo Código do Direito de Autor e Direitos Conexos e demais legislação aplicável, toda a cópia, parcial ou total, deste documento, nos casos em que é legalmente admitida, deverá conter ou fazer-se acompanhar por este aviso.

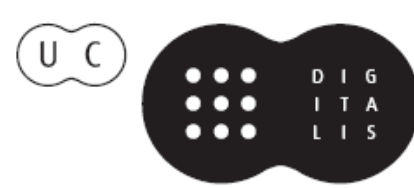




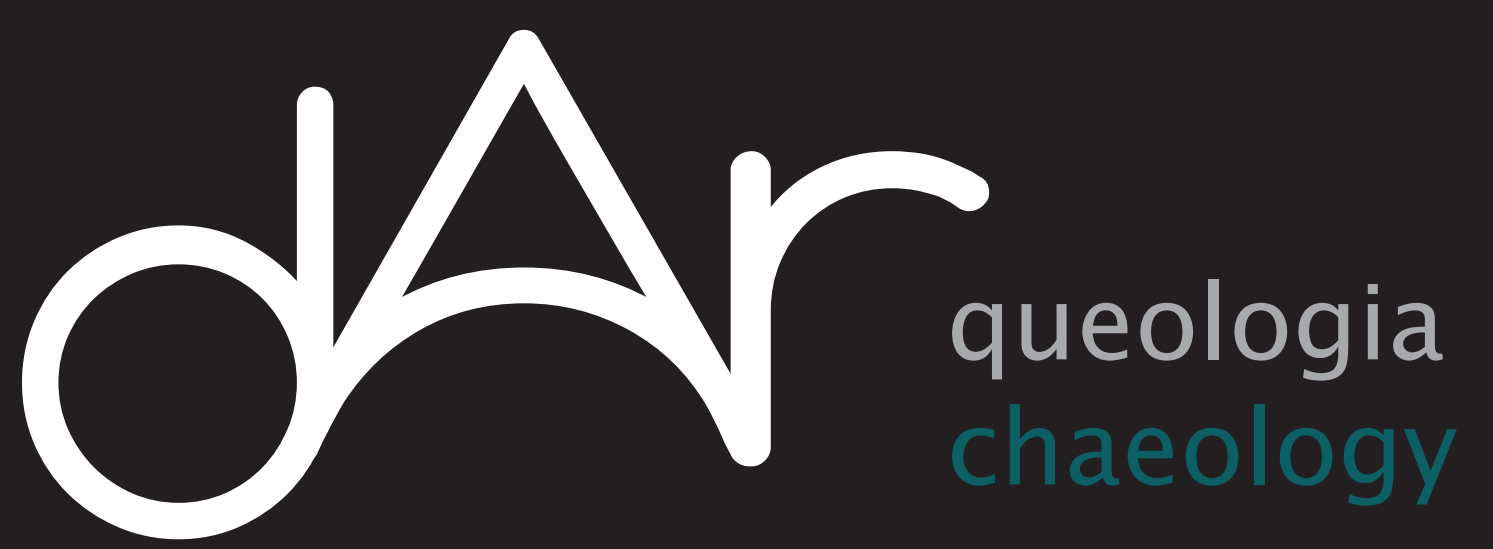

q

ig

u

논

e s

it<smiles>c1ccccc1</smiles>

$\mathrm{S}$

al $t \mathrm{t}$

e e

C C

t $\mathrm{t}$

u

c

\section{chaeology}

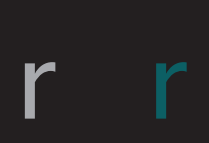

a e

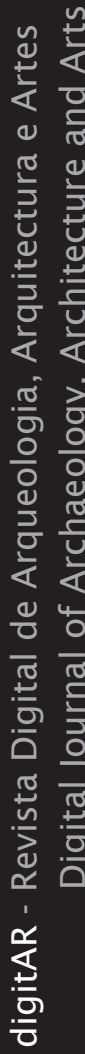




\section{METHODOLOGICAL APPROACH AND FIRST RESULTS OF USE-WEAR TRACES ON FLINT TOOLS THROUGH CONFOCAL MICROSCOPE.}

\author{
Claudia Santamaría Cabornero, \\ Sergio Miguel Luengo Cortés, \\ Marta Navazo Ruiz \\ Department of History, Geography and \\ Comunication, Burgos University, Burgos, Spain.
}

\author{
Alfonso Benito-Calvo, \\ Centro Nacional de Investigación sobre la \\ Evolución Humana (CENIEH), Paseo Sierra de \\ Atapuerca 3, 09002, Burgos, Spain \\ Ignacio Martín Lerma \\ Department of Prehistory, University of Murcia, \\ Murcia, Spain
}

\section{RESUMEN}

En este trabajo se analiza el potencial del microscopio confocal de barrido laser (LSCM) para el análisis traceológico de materiales líticos. Esta clase de estudios tratan de identificar las marcas de uso en las herramientas líticas con el fin de conocer las diferentes actividades llevadas a cabo por grupos humanos durante la Prehistoria. Así pues planteamos el análisis microscópico mediante microscopio confocal como un avance en la cuantificación de marcas o patrones de superficie, consiguiendo resultados favorables para el análisis traceológico, y por extensión para la Arqueología prehistórica.

Palabras clave: microscopio confocal, huellas de uso, tecnología lítica.
Key words: Laser Scanning Confocal Microscopy, use wear analysis, lithic technology 


\section{Introducción}

En este trabajo buscamos aplicar una relativamente novedosa metodología en el ámbito de la arqueología para comprobar sus utilidades potenciales en esta disciplina. Para ello, se ha realizado un inicial estudio traceológico, en un primer momento de un conjunto lítico experimental, y posteriormente de una pequeña parte del conjunto lítico musteriense recuperado en el yacimiento de Prado Vargas (Burgos, España). El análisis de las huellas de uso o traceología es una disciplina que implica el estudio sobre las marcas creadas en la industria tras su aplicación sobre distintos materiales (Martín Lerma, 2008). La funcionalidad y uso de las herramientas en un yacimiento ha sido siempre uno de los paradigmas en los estudios arqueológicos y el estudio sobre las huellas de uso de los instrumentos utilizados por grupos humanos pasados nos ofrece valiosa información, permitiendo establecer una relación casi directa con la herramienta y su uso real. Esta disciplina busca responder a cómo, para qué y sobre qué se usan las herramientas (Vicente Santos, 2010). En este trabajo nos hemos enfocado en este último punto. En los últimos años han comenzado a realizarse estudios traceológicos mediante el uso de nuevas tecnologías en estos ámbitos capaces de cuantificar información. Incluye una gran variedad de microscopios y si bien aún queda mucho campo por descubrir, se están poniendo en práctica varios estudios científicos que buscan determinar cuál es la mejor metodología en relación a la microscopía, avanzando especialmente en los métodos cuantitativos que nos permiten objetivar más en la identificación de la actividad realizada (Stemp et al., 2013). En nuestro caso, buscamos comprobar la aptitud del microscopio confocal para este tipo de trabajos, cuyo acceso nos ha facilitado el Centro Nacional de Investigación sobre la Evolución Humana (CENIEH), en Burgos. Estableceremos unas ventajas y unos inconvenientes con lo preexistente. Para este estudio hemos empleado las herramientas básicas del microscopio confocal, consistiendo más en una exploración de todas sus capacidades potenciales para la Arqueología, que un estudio en profundidad del mismo. Prado Vargas es un yacimiento en cueva incluido en el complejo kárstiko de Ojo Guareña. Se ubica cerca de la localidad de Cornejo (Burgos), en la vertiente sur de la Cordillera Cantábrica de la Península Ibérica. Cuenta con indicios de haber sido ocupada tanto por humanos como por animales (Navazo Ruiz et al., 2005). Su cronología se corresponde con más de 46.000 años (Navazo Ruiz \& Díez Fernández-Lomana, 2008). Contiene principalmente sílex cretácico autóctono, de las inmediaciones de la cueva. El conjunto lítico se encuentra en buen estado de conservación y no parece haber rodamiento, aunque la presencia de pátina es común. La mayor parte del material recuperado está representado por lascas, presentando también algún conjunto de retocados y núcleos y algunas bases naturales de las que sólo dos han sido usadas (Navazo Ruiz \& Díez Fernández-Lomana, 2008). Encontramos, por tanto, tres pasos de la cadena operativa en el interior de la cueva: talla de las herramientas, uso y posterior abandono. El uso de las herramientas se relaciona con los restos óseos con marcas de corte encontrados, cuyas partes más aprovechables parece ser ya has sido primeramente seleccionados en el exterior (Navazo Ruiz et al., 2005).

\section{MATERIAL Y MÉTODOS}

\subsection{Muestra arqueológica}

Con el objetivo de aplicar el microscopio confocal para la identificación de huellas de uso se ha seguido el siguiente protocolo: se ha realizado una selección de piezas arqueológicas del yacimiento de Prado Vargas basándonos en la calidad del material, pues cuanto más fino sea el grano, más probabilidades tiene de presentar desgaste por uso, especialmente el pulimento (González Urquijo \& Ibáñez Estévez, 1994). La materia más representativa de las herramientas líticas del yacimiento y óptima para este estudio 


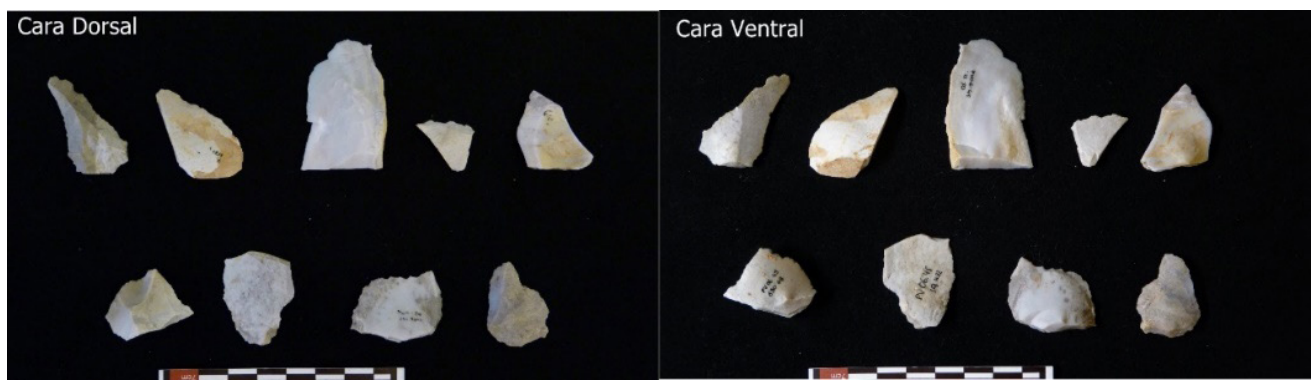

Figura 1- colección arqueológica estudiada, 9 piezas de sílex procedentes del nivel 4 de Prado Vargas.

es el sílex de formación cretácica, conjunto del que hemos seleccionado 8 lascas y una raedera, todas provenientes del nivel 4 . El protocolo que hemos seguido para realizar la identificación ha sido, en el caso de las piezas arqueológicas, tras el análisis tecnológico un proceso de limpieza en cubeta ultrasónica en agua templada desionizada y detergente, acción que ha resultado continuada cada vez que se contaminaba la muestra al posicionarse correctamente sobre el microscopio. Posteriormente se ha llevado a cabo una rápida observación en la lupa binocular para establecer las zonas potenciales de desgaste y tras esto, un estudio más detallado de las mismas en el microscopio confocal. Se han definido las características más relevantes que presentan las piezas estudiadas. En un primer momento se describieron los rasgos tecnológicos de cada pieza: breve descripción con sus características particulares, material y dimensiones. Posteriormente se establecieron las principales zonas morfopotenciales, es decir las partes de una pieza más potencialmente susceptibles a ser utilizadas en diferentes actividades en función de su estructura (Airvaux, 1987; 1994; Carbonell, 1987; Carbonell et al. 1992), por dónde se extenderían las huellas de uso si las hubiera, tratando de discriminar cada particularidad, para establecer una relación con la materia sobre la que se ha trabajado. El conjunto lítico ha resultado ser bastante homogéneo y de buena calidad. Son, en su gran mayoría, lascas sin retoque (BP), a excepción de un retocado (ver imagen $n^{\circ}$ 1). No se aprecia presencia de córtex en ninguna pieza y todas ellas presentan talón plataforma y un tamaño medio de 26×20×8.

\subsection{Muestra experimental}

Tras el análisis tecnológico se escogió un conjunto de la misma materia prima con la que se fabricaron las herramientas arqueológicas de Prado Vargas (Vallejo

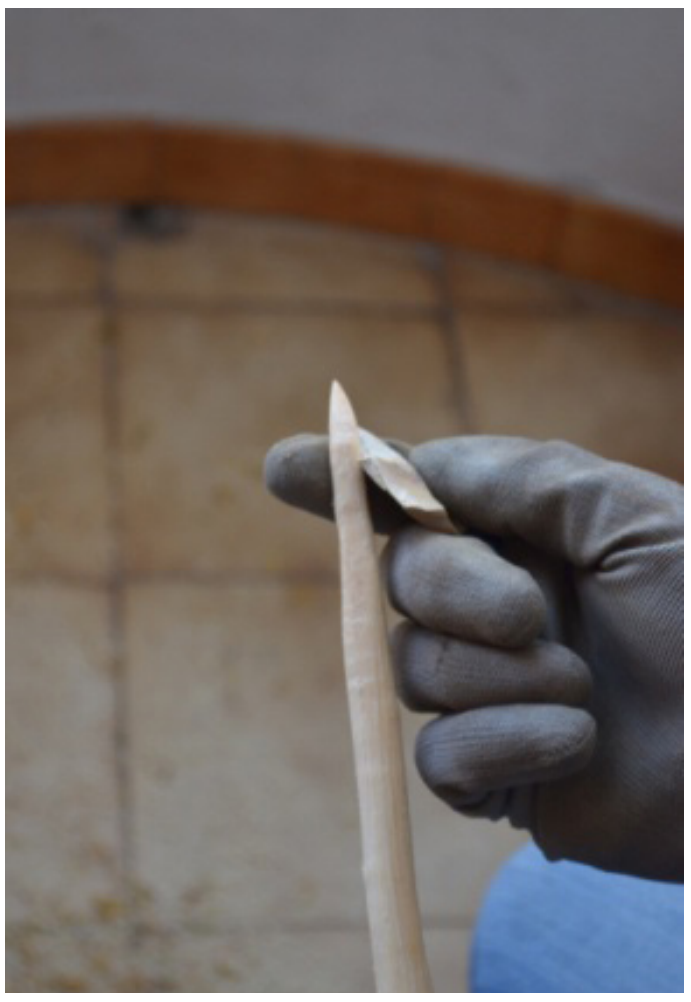

Figura 2- Afilado de vara de roble con lasca sin retoque experimental 


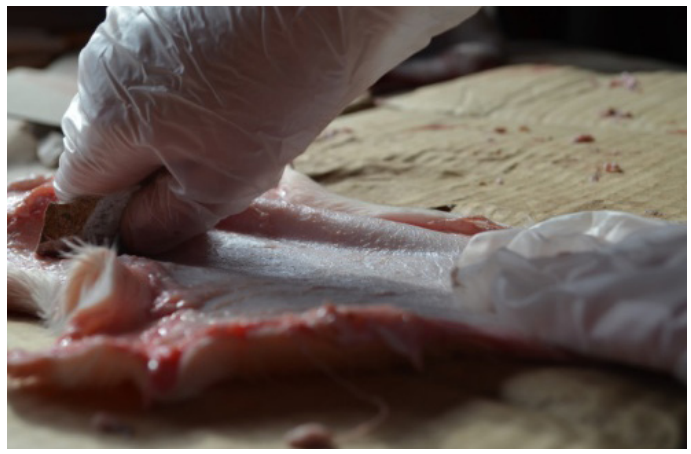

Figura 3- Raspado de piel con raedera experimental

et al, 2015). En total se reprodujeron un conjunto de 13 piezas experimentales.

Las piezas experimentales fueron manufacturadas acorde a las piezas arqueológicas recuperadas del yacimiento, buscando que compartieran la mayor similitud posible con las muestras arqueológicas, y en sílex autóctono. Posteriormente se seleccionó la muestra más representativa de la colección y se tomó un registro de los filos y zonas potenciales previo uso mediante el microscopio confocal para conocer la disposición de la superficie sin modificar por el uso.

A continuación se utilizaron las piezas sobre las materias más vinculadas al modo de vida económico cazador-recolector de los grupos neandertales del Paleolítico Medio: procesamiento de materias orgánicas animales como carne y pieles, así como materias orgánicas vegetales arbóreas. Las actividades de procesamiento fueron descortezar, serrar y afilar una vara de madera (ver imagen $n^{\circ}$ 2) y cortar carne, piel, y raspado de pieles por ambos lados (ver imagen $n^{\circ} 3$ ). Mediante dichos trabajos se tuvieron en cuenta movimientos tanto unidireccionales como bidireccionales, así como acciones continuas o discontinuas durante las utilizaciones de los útiles.

El Programa Experimental se llevó a cabo atendiendo a un protocolo que contemplara múltiples variables en juego: tiempo, materia prima materia trabajada, actividad, tipo de filo o retoque y ángulo del filo. El resto de procedimiento metodológico e instrumental para limpieza y análisis microscópico fue idéntico al llevado a cabo con los ejemplares arqueológicos.

\subsection{Microscopio confocal}

Para los análisis se tuvieron en cuenta cuatro variables dependientes: estrías, pulimento, desconchados y embotamiento del filo, otorgándole mayor valor diagnóstico a las dos primeras. El microscopio empleado es un LEXT 3100 OLS, microscopio confocal de barrido laser (LSCM), una técnica no destructiva que permite su aplicación sobre gran variedad de materiales sin preparación previa (Macdonald, 2014). En los últimos años ha aumentado su uso en aplicaciones arqueológicas (Stemp \& Chung; 2011; Stemp et al. 2013; Ibáñez et al. 2014; Reinosa et al. 2015). Es un microscopio óptico, con el mismo o similar rango de aumentos en las lentes que estos microscopios, entre 2,5X y 200X. Sin embargo su diferencia más notoria frente a los microscopios ópticos convencionales es que solo recepta luz proveniente de un punto concreto de la muestra, el plano focal (Evans \& Donahue, 2008). El principio básico del microscopio confocal es que emplea una gran potencia de luz mediante barrido. Es aplicada a través un sistema láser enfocada sobre una parte muy concreta en el objeto de estudio desde un plano focal discontinuo (Evans \& Donahue, 2008). Este microscopio registra las imágenes a través de la posición de la luz mediante un pinhole (Stemp et al, 2013), proporcionando información sobre la altura de las diferentes superficies que posteriormente se unen generando una imagen. Todos los registros de imágenes obtenidos, tanto en 2D como en 3D, van acompañados de medidas o escalas a micrómetros para facilitar la medición de determinadas zonas o variables del sector de la pieza registrado. Por otra parte las imágenes en 3D están incluidas dentro de un cuadrante que engloba 


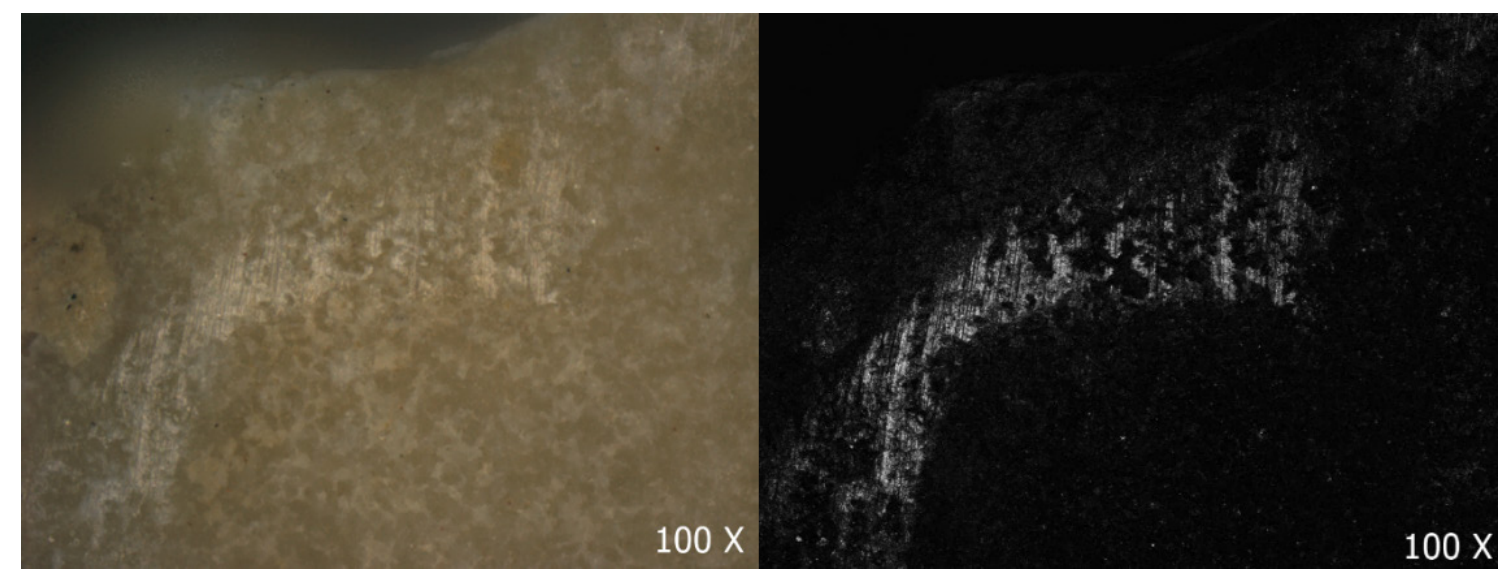

Figura 4- estrías y pulimento de materia dura en imagen 2D (izquierda) y en opción intensidad (derecha).

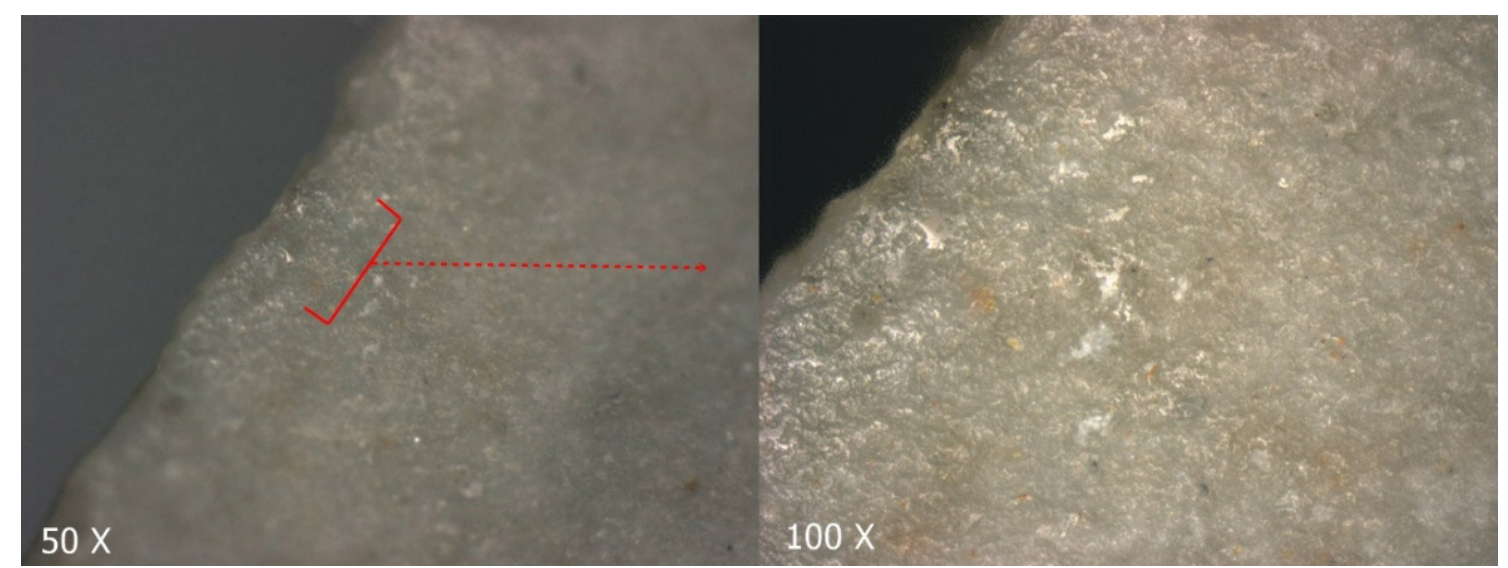

Figura 5- detalle en 3D de pulimento a diferentes aumentos, manteniendo la resolución

todo el sector, con determinadas medidas en horizontal-X-, en vertical $-Y-$, y en altura -Z- a escala en función del aumento. A través de las imágenes registradas se pueden elaborar perfiles topográficos tanto en horizontal como en vertical (ver imagen $n^{\circ} 6$ ), acompañados además de medidas de longitud y altura a escala según el aumento. Permite medir la distancia entre dos puntos concretos, así como calcular las dimensiones de un área determinada, efectuar análisis geométricos, de partículas, de volumen y de rugosidad entre otros, este último muy útil para medir los patrones topográficos de la superficie analizada, obteniendo datos sobre altura máxima, profundidad máxima, altitud media, etc. Por lo tanto el análisis de superficie tridimensional que proporciona el microscopio confocal sería ideal para la documentación de marcas de uso, proporcionando una resolución superior que otros sistemas para cuantificar, como el microscopio de foco variable (VFM), o el microscopio de fueza atómica (AFM) (Stemp. 2014). A través de él se ha comprobado la posibilidad 

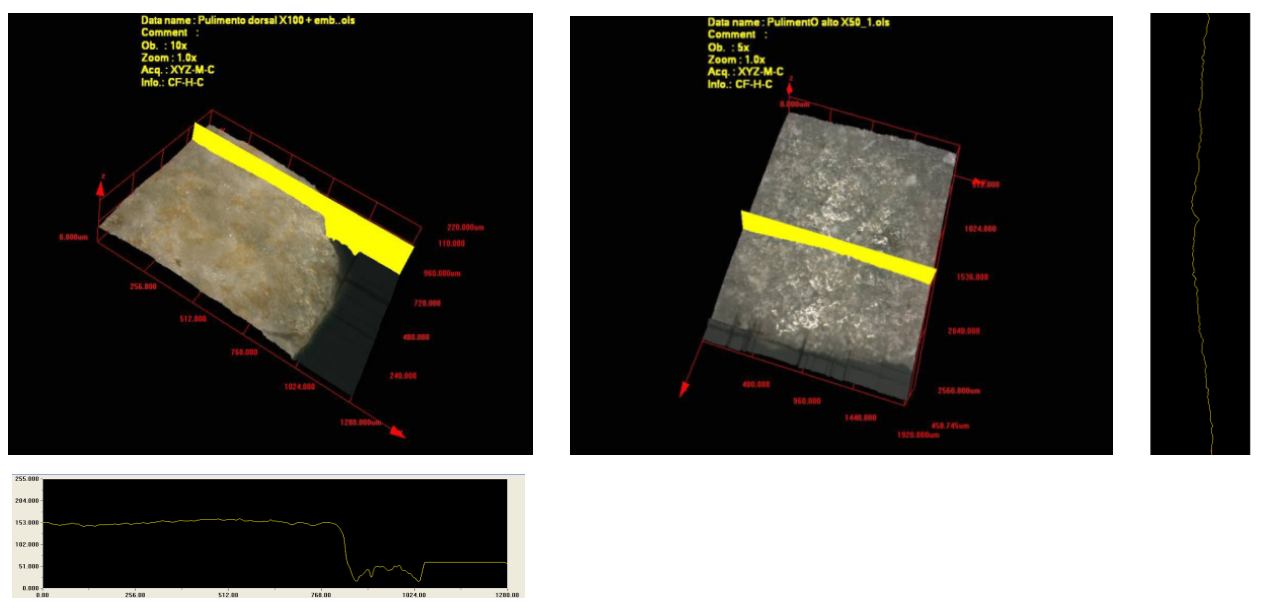

Figura 6- perfiles topográficos en 3D realizados mediante microscopio confocal sobre superficies de lascas experimentales (BP); perfil en eje X (izquierda), y perfil en eje Y (derecha).

de observar diferencias significativas entre actividades o procesamiento de materiales de similares características, incluso entre el lustre de cereal de las variedades silvestre o doméstica de la misma especie (lbáñez et al. 2014), siendo cada vez más ampliamente usado para medir la topografía de superficie con una alta precisión de rango micrométrico (Mueller et al. 2016).

\section{RESULTADOS}

Se ha podido comprobar la relativa rapidez en la formación de huellas de uso sobre este tipo de sílex, pues hemos observado estas huellas de usodesgaste tanto a nivel macro, en el caso de los desconchados, como a nivel micro en el caso de pulidos, estrías y embotamientos (ver imagen $n^{\circ} 4$ y $n^{\circ} 5$ ).

Sin embargo hay una gran variabilidad en el grado desarrollo y frecuencia de aparición de las marcas de uso, especialmente pulimentos o embotamientos, ya que además del tipo de actividad, la materia prima o la materia trabajada importan también las características morfopotenciales de las zonas activas de cada herramienta.
En este sentido el microscopio confocal se ha revelado como una herramienta muy útil para el estudio traceológico, permitiendo la observación detallada a varios niveles gracias la variabilidad de aumentos (ver imagen $n^{\circ} 5$ ). Varios estudios actuales enfocados a la Arqueología, o con aplicaciones arqueológicas sobre diversos materiales como sílex (lbáñez et al. 2014), cuarcita (Stemp et al. 2012), cuarzo (Reinosa et al. 2015), obsidiana (Stemp \& Chung. 2011), hueso (Nishikawa et al. 2012), cerámica (Reinosa et al. 2015) se han valido del microscopio confocal como herramienta de estudio. Todo ello para tratar de obtener más precisión en sus conclusiones respecto a los patrones paleconómicos a través de la cuantificación (Mazzuco \& Gibaja 2016). Las ventajas que entraña el microscopio confocal son varias: corto tiempo de escaneo, fácil de usar, versátil, produce imágenes de color reales, además de imágenes, perfiles o modelos 3D (ver imagen $n^{\circ} 6$ ) en grado de intensidad de brillo, y altura; permite además obtener excelentes resoluciones laterales, uno de los punto críticos de los microscopios ópticos de luz reflejada. 
Con todo, las principales cualidades de esta tecnología para la Arqueología son, por un lado la alta resolución en los modelos 3D que elabora, y por otro lado, la capacidad de obtener resultados cuantitativos analizando la topografía registrada en base a diferentes tipos de análisis, especialmente de rugosidad.

\section{CONCLUSIONES}

En nuestra opinión, no creemos que se haya llegado a una metodología definitiva. Los propios blind-test aportan un $70 \%$ de fiabilidad a la hora de establecer la materia sobre la que se han trabajado las herramientas (Calvo Trías, 2002). Si bien no es una cifra desdeñable, desde lvego es mejorable, y gran parte de ese rango de mejora se encuentra en la subjetividad que puede condicionar esta disciplina y que es posible paliar mediante la cuantificación posibilitada por el microscopio confocal.

El microscopio confocal ha resultado muy útil para el análisis traceológico sobre marcas de uso en herramientas líticas, con un alto grado de resolución no solo en las superficies planas, sino también en superficies inclinadas o en el borde del artefacto, como los filos, y por supuesto por la capacidad de medir patrones geográficos sobre la superficie, ofreciendo la posibilidad de realizar análisis cuantitativos, mucho más objetivos, así como por su relativa rapidez a la hora de reproducir modelos 3D. Por tanto, podemos afirmar que la metodología aplicada supone una mejora en la sistematización de esta disciplina por sus posibilidades cuantitativas y la alta resolución en los modelos 3D, muy útiles para el análisis microscópico sobre artefactos arqueológicos. Sin embargo, no hay que olvidar que la misma está aún en desarrollo y que las aplicaciones arqueológicas que ofrece aún se encuentran en perfeccionamiento. Por eso nos ha parecido interesante conocer los límites y las ventajas que ofrece el microscopio a este ámbito traceológico, pues con un progreso adecuado pueden aportar información de forma más fiable, suponiendo una mejora al conocimiento de las actividades que llevarían a cabo

los grupos humanos prehistóricos.

\section{AGRADECIMIENTOS}

Este trabajo se ha podido realizar gracias a los equipos prestados por el CENIEH y el CAREX. Gracias también a la colaboración de Marcos Terradillos y Felipe Cuartero por la reproducción de piezas experimentales, y a Marta Santamaría y Adelina Matilla por el trabajo realizado.

\section{BIBLIOGRAFÍA}

Airvaux, J. 1987. "Les potentialités morphologiques". In (E. Carbonell, M. Guilbaud \& R. Mora, Eds) Sistemes d'anàlisi en Prehistòria, pp. 17-67. Girona: Centre de Recerques Paleo-ecosociales (CRPES).

Airvaux, J. 1994. "Aspectos teóricos de la evolución de las industrias líticas". In (J. M. Merino, Eds) Tipología lítica, pp. 437-455. San Sebastián: Sociedad de Ciencias Aranzadi.

Calvo Trías, M., 2002. Útiles líticos prehistóricos. Forma, función y uso. Ariel, Bacelona.

Carbonell, E. 1987. "Human Development in the framework of the Lithic Operative Chains". In (E. Carbonell, M. Guilbaud \& R. Mora, Eds) Sistemes d'anàlisi en Prehistòria, pp. 68-82. Girona: Centre de Recerques Paleoecosocials (CRPES).

Carbonell, E., Mosquera, M., Ollé, A., Rodríguez, X. P., Sala, R., Vaquero, M. \& Vergès, J. M. 1992. "New Elements of the Logical Analytic System". Cahier noir 6: 3-61.

Evans A. A, Donahue R. E, 2008. "Laser scanning confocal microscopy: a potential technique for the study of lithic microwear". Journal of Archaeological Science 35, 2223-2230.

González Urquijo, J.E., Ibáñez Estévez, J.J., 1994. Metodología de análisis funcional de instrumentos tallados en sílex. Artes Gráficas Rontegui, Bilbao.

Ibáñez J. J, González-Urquijo J. E, Gibaja J. 2013. "Discriminating wild vs domestic cereal harvesting micropolish through laser confocal microscopy". Journal of Archaology Science xxx, 1-8.

Macdonald D., 2014. "The application of focus variation microscopy for lithic usewear quantification". Journal of Archaeological Science. 48, 26-33.

Martín Lerma, I., 2008. "Análisis microscópico de la industria lítica: La traceologia". Panta Rei III. $15-25$.

Mazzuco N, Gibaja J. F. 2016. "A palaeoeconomic perspective on the Early Neolithic lithic assemblages of the N-NE of the Iberian Peninsula". Quaternary International xxx, 1-10.

Mueller T, Jordan M, Schneider T, Poesch A, Reithmeier E. 2016. "Measurement of steep edges and undercuts in confocal microscopy". Micron 84, 79-95. 
Navazo Ruiz, M., Díez Fernández-Lomana, J.C., 2008. "Prado Vargas y la variabilidad tecnológica a finales del Paleolítico Medio en la meseta norte". Treballs d'Arqueologia. 14, 121-139.

Navazo Ruiz, M., Díez Fernández-Lomana, J.C., Torres, T., Colina, A., Ortiz, J.E., 2005. "La Cueva de Prado Vargas: Un yacimiento del Paleolítico Medio en el Sur de la Cordillera Cantábrica". 20, 151-166.

Nishikawa T, Kokubu M, Kato H, Imai K, Tanaka A. 2012. "Confocal laser scanning microscopy in study of bone calcification". Applied Surface Science 262, 64-68.

Reinosa J.J, del Campo A, Fernández J. F, 2015. "Indirect measurement of stress distribution in quartz particles embedded in a glass matrix by using confocal Raman microscopy". Ceramics International 41, 13598-13606.

Stemp, W.J., Chung, S., 2011. "Discrimination of surface wear on obsidian tools using LSCM and RelA: pilot study results (area-scale analysis of obsidian tool surfaces)". Scanning 33 (5), 279-293.

Stemp,W.J., Lerner, H.J., Kristant, E.H., 2013.

"Quantifying microwear on experimental Mistassini quartzite scrapers: preliminary results of exploratory research using LSCM and scalesensitive fractal analysis". Scanning 35 (1), 28-39.

Stemp W. J. 2014. "A review of quantification of lithic use-wear using laser profilometry: a method based on metrology and fractal analysis". Journal of Archaeological Science $48,15-25$.

Vallejo, S. et al., 2015. "Characterization and supply of raw materials in the Neanderthal groups of Prado Vargas Cave(Cornejo, Burgos, Spain)", Quaternary International.

Vicente Santos, F.J., 2010. El estudio de las marcas de uso, un gran desconocido. El Futuro del Pasado. 1, 97-107. 